\title{
Bioactivity, biocompatibility and phytochemical assessment of lilac sage, Salvia verticillata L. (Lamiaceae) - A plant rich in rosmarinic acid
}

\author{
Jelena S. Katanić Stankovića,*, Nikola Srećkovićb ${ }^{\mathrm{b}}$, Danijela Mišićc ${ }^{\mathrm{c}}$ Uroš Gašićc,d, Paola Imbimbo ${ }^{\mathrm{e}}$, \\ Daria Maria Monti ${ }^{\mathrm{e}}$, Vladimir Mihailović ${ }^{\mathrm{b}}$ \\ ${ }^{a}$ Institute for Information Technologies Kragujevac, Department of Science, University of Kragujevac, Jovana Cvijića bb, 34000 Kragujevac, Serbia \\ ${ }^{\mathrm{b}}$ Department of Chemistry, Faculty of Science, University of Kragujevac, Radoja Domanovića 12, 34000 Kragujevac, Serbia \\ " Institute for Biological Research "Siniša Stanković” - National Institute of Republic of Serbia, University of Belgrade, Bulevar despota Stefana 142, 11060 Belgrade, Serbia \\ ${ }^{\mathrm{d}}$ University of Belgrade, Faculty of Chemistry, P. O. Box 51, 11158 Belgrade, Serbia \\ ${ }^{\mathrm{e}}$ Department of Chemical Sciences, University of Naples Federico II, Complesso Universitario Monte Sant'Angelo, via Cinthia 4, 80126 Naples, Italy
}

\section{A R T I C L E I N F O}

\section{Keywords:}

Salvia verticillata $\mathrm{L}$.

Lilac sage

Antioxidant

Antimicrobial

Biocompatibility

Phytochemical analysis

\begin{abstract}
A B S T R A C T
The plants from genus Salvia, as one of the largest genus in Lamiaceae family, are frequently in use for various purposes, as foods, in cosmetic industry, or in traditional and official medicine. Salvia verticillata L. (liliac sage) is one of sidelined sage species with potential bioactivity, reported in traditional medicine. The aim of this study was to acquire a phytochemical profile of the methanol extract obtained from $S$. verticillata aerial parts and to evaluate its antioxidant, antimicrobial, and biocompatibility potential. Characteristic compounds of the genus Salvia, such as rosmarinic and caffeic acids, along with their derivatives (e.g. salvianolic and yunnaneic acids isomers) and flavonoids, have been identified by ultrahigh-performance Orbitrap metabolomic fingerprinting as the main phenolic metabolites in $S$. verticillata. The extract displayed moderate antimicrobial properties and significant antioxidant potential, with the half maximal inhibitory concentration values $\left(\mathrm{IC}_{50}\right)$ ranging from 33 to $73 \mu \mathrm{g} / \mathrm{mL}$. Importantly, full biocompatibility of the extract with eukaryotic cell lines was observed up to $72 \mathrm{~h}$. The obtained results revealed the presence of polyphenolic bioactive compounds in $S$. verticillata extract with promising antioxidant potential and significant biocompatibility. In this regard, $S$. verticillata can find new perspectives of application as a food ingredient, in cosmetic and pharmaceutical industries, as it represents a valuable source of compounds with prominent health properties, with a special focus on rosmarinic acid.
\end{abstract}

\section{Introduction}

The genus Salvia, the largest genus in the Lamiaceae family, consists of over a thousand plant species distributed worldwide (Lu and Yeap Foo, 2002; Walker et al., 2004). The name of the genus was derived from the Latin word "salvare", which means "to heal/to save" (Topçu, 2006). The Salvia species are aromatic plants used as food spices and culinary herbs, as tea, in cosmetic industries, and in traditional medicine because of their bioactive properties (Ghorbani and Esmaeilizadeh, 2017). Since ancient times, the most known and most used Salvia spp. is a common sage (Salvia officinalis L.). This sage is used as a spice in food products, in traditional medicine for different ailments such as hemorrhage, menstrual disorders like dysmenorrhea, against tuberculosis, as well as in the treatment of numerous inflammatory diseases, dyspepsia, diarrhea, age-related cognitive disorders, tremor, excessive sweating, and hyperglycemia (EMA, 2016; Ghorbani and
Esmaeilizadeh, 2017; Sharifi-Rad et al., 2018; Topçu, 2006). Besides $S$. officinalis, many other plants from genus Salvia are in use due to their biological benefits. For example, roots of red sage (Salvia miltiorrhiza Bunge) are highly respected and widely utilized in the treatment of cardiovascular and cerebrovascular diseases (Chen and Chen, 2018; Zhang et al., 2016). Also, chia seeds (Salvia hispanica L.) are used worldwide for their multifunctional properties and benefits to human health (Parker et al., 2018). One Salvia spp. that is marginalized from the use in modern pharmacological and functional food formulations is Salvia verticillata $\mathrm{L}$.

Salvia verticillata L., called "lilac sage" or even "purple rain", is a herbaceous perennial herb with tiny lilac-blue flowers which grow tightly packed in whorls (Forouzin et al., 2015). This plant has been employed in the cheese-making process to obtain specific taste and for the preservation of meat products and cheese (Topçu, 2006). In Serbia, this herb is known by the name "sjeruša" that indicates its use for

\footnotetext{
* Corresponding author.

E-mail address: jkatanic@kg.ac.rs (J.S. Katanić Stanković).
} 
flavoring in cheese production. In traditional Serbian medicine, $S$. verticillata tea, made from its aerial parts, has been used as an expectorant, for disinfection of the oral cavity and as cataplasm for healing wounds (Jarić et al., 2015).

The chemical composition of Salvia plants is mostly comprised of several groups of secondary metabolites: terpenes (mono-, di-, and triterpenes), phenolic compounds (flavonoids and phenolic acids), and saccharides (Ghorbani and Esmaeilizadeh, 2017; Lu and Yeap Foo, 2002; Topçu, 2006; Xu et al., 2018). Moreover, a wide range of terpenoid compounds (e.g., tanshinones, camphor, caryophyllene, borneol, $\alpha$ - and $\beta$-thujone) and polyphenolics (with characteristic high content of rosmarinic acid, caffeic acid and its metabolites salvianolic and yunnaneic acids) detected in Salvia spp. were found to endow a vast array of recorded bioactivities (Ghorbani and Esmaeilizadeh, 2017; Jassbi et al., 2016; Lu and Yeap Foo, 2002; Sharifi-Rad et al., 2018; Topçu, 2006; Wu et al., 2012; Xu et al., 2018).

In this respect, the aim of the presented study was to thoroughly investigate the phytochemical profile of methanol extract obtained from $S$. verticillata aerial parts (herein denoted as SV), to quantify targeted compounds, to evaluate its antioxidant and antimicrobial properties (antibacterial and antifungal), as well as its cytotoxicity on different cancer and immortalized cell lines.

\section{Materials and methods}

\subsection{Chemicals}

The reagents and chemicals used in the assays for evaluation of total phenolic compounds, antioxidant and antimicrobial activities were purchased from Sigma Aldrich (Steinheim, Germany) and Alfa Aesar (Karlsruhe, Germany). Nutrient agar (NA), Sabouraud dextrose agar (SDA), Müller-Hinton broth (MHB), and Sabouraud dextrose broth (SDB) were purchased from Torlak Institute of Virology, Vaccines and Sera (Belgrade, Serbia). Standards of 5-O-caffeoylquinic acid (chlorogenic acid), caffeic acid, quercetin 3-O-rutinoside (rutin), quercetin 3$O$-rhamnoside (quercitrin), rosmarinic acid, salvianolic acid B, apigenin-7-O-glucoside (apigetrin), apigenin, carnosol, and carnosic acid were purchased from Sigma Aldrich (Steinheim, Germany).

\subsection{Plant material and extract preparation}

The aerial parts of Salvia verticillata L. (Lamiaceae) were collected in July 2016 during flowering season in the area of village Prijevor $\left(43^{\circ} 55^{\prime} 19.3^{\prime \prime} \mathrm{N} 20^{\circ} 15^{\prime} 14.5^{\prime \prime} \mathrm{E}\right)$, near the Ovčar-Kablar Gorge (Western Serbia) by J. S. Katanić Stanković. A voucher specimen (No. 125/016) was deposited in the Herbarium of the Department of Biology and Ecology, Faculty of Science, University of Kragujevac (Kragujevac, Serbia). Taxonomic and botanical identification was confirmed by Dr. Milan S. Stanković. The air-dried S. verticillata aerial parts (130 g) were fine powdered and macerated with methanol at the room temperature for $24 \mathrm{~h}$ three times $(500 \mathrm{~mL}$ each). The extract was filtered and the solvent was entirely removed using the rotary evaporator (RV 10 basic, IKA, Staufen, Germany) under low pressure to obtain the dry extract. The final weight of $S$. verticillata dry extract (SV) was $16.8 \mathrm{~g}$. The percentage yield of SV was found to be $12.92 \%(w / w)$. The concentrations used in the experiments were based on the dry weight of the extract.

\subsection{Determination of phenolic compounds}

\subsubsection{Total phenolic content (TPC)}

The total phenolic content was estimated according to Singleton et al. (1999). Concisely, in $0.5 \mathrm{~mL}$ of SV extract $(0.5 \mathrm{mg} / \mathrm{mL}) 2.5 \mathrm{~mL}$ of Folin-Ciocalteu reagent (diluted 10-fold) and $2 \mathrm{~mL}$ of $\mathrm{NaHCO}_{3}(7.5 \%)$ were added. The absorbance was measured at $765 \mathrm{~nm}$ on UV-Vis double beam spectrophotometer Halo DB-20S (Dynamica GmbH, Dietikon, Switzerland) with temperature control after $15 \mathrm{~min}$ of incubation. TPC value was expressed as gallic acid equivalents (mg GA/ g dry extract).

\subsubsection{Total flavonoids content}

The total flavonoid content was determined using the $\mathrm{AlCl}_{3}$-method according to Brighente et al. (2007). The aluminum trichloride solution $\left(0.5 \mathrm{~mL}, 2 \% \mathrm{AlCl}_{3}\right)$ and the same volume of a methanol solution of SV $(0.5 \mathrm{mg} / \mathrm{mL})$ were incubated for $1 \mathrm{~h}$ at room temperature and the absorbance was measured at $415 \mathrm{~nm}$. The total flavonoid content was expressed as rutin equivalents (mg RU/g extract).

\subsubsection{Total flavonols content}

Total flavonols content in the extract was evaluated by the method of Yermakov et al. (1987). The SV extract $(1 \mathrm{~mL}, 1 \mathrm{mg} / \mathrm{mL}$ ) was mixed with $\mathrm{AlCl}_{3}(1 \mathrm{~mL}, 2 \%)$ and sodium acetate $(3 \mathrm{~mL}, 50 \mathrm{mg} / \mathrm{mL})$. The absorbance was read after $2.5 \mathrm{~h}$ at $440 \mathrm{~nm}$. The content of flavonols was calculated as rutin equivalents and expressed as $\mathrm{mg} \mathrm{RU} / \mathrm{g}$ extract.

\subsubsection{Total phenolic acids content}

Total phenolic (hydroxycinnamic) acids content was adopted from Polish Pharmacopoeia as reported by Matkowski et al. (2008). Distilled water $(5 \mathrm{~mL})$ was added to $\mathrm{SV}$ ( $1 \mathrm{~mL}, 1 \mathrm{mg} / \mathrm{mL})$. Thereafter, the mixture of $\mathrm{HCl}(1 \mathrm{~mL}, 0.1 \mathrm{M})$, Arnow reagent $(1 \mathrm{~mL}, 10 \% \mathrm{w} / \mathrm{v}$ of sodium molybdate and $10 \% \mathrm{w} / \mathrm{v}$ sodium nitrite) and $\mathrm{NaOH}(1 \mathrm{~mL}, 1 \mathrm{M})$ was added and filled up to $10 \mathrm{~mL}$. The absorbance was read immediately at $490 \mathrm{~nm}$. The result was expressed as caffeic acid equivalents (mg CA/g extract).

\subsection{UHPLC/MS-MS orbitrap analysis}

Separations of compounds of interest were performed using an ultrahigh-performance liquid chromatography (UHPLC) system consisting of a quaternary Accela 600 pump and Accela autosampler (ThermoFisher Scientific, Bremen, Germany). A Syncronis C18 column $(100 \times 2.1 \mathrm{~mm}, 1.7 \mu \mathrm{m}$ particle size $)$, thermostated at $40^{\circ} \mathrm{C}$, was used for compounds separation. The flow rate was set to $300 \mu \mathrm{L} / \mathrm{min}$ and the mobile phase consisted of $0.1 \%$ acetic acid in water (A) and acetonitrile (B). The injection volumes were $5 \mu \mathrm{L}$ and the linear gradient program was previously described (Božunović et al., 2018).

The UHPLC system was coupled to a linear ion trap - orbitrap mass spectrometer (LTQ OrbiTrap MS) equipped with heated electrospray ionization probe (HESI-II, ThermoFisher Scientific, Bremen, Germany) operating in negative ionization mode. Parameters of the ion source were as in the literature (Božunović et al., 2018). The MS spectra were acquired by full-range acquisition covering 100-1000 m/z. The resolution was set to 30.000 for full scan analysis. The data-dependent MS/ MS events were always performed on the most intense ions detected in the full scan MS. The ions of interest were isolated in the ion trap with an isolation width of $3 \mathrm{ppm}$ and activated with $35 \%$ collision energy levels.

Xcalibur software (version 2.1) was used for the instrument control, data acquisition, and analysis. The identification of unknown compounds was done by exact mass search of their deprotonated molecule $\left([\mathrm{M}-\mathrm{H}]^{-}\right)$and its $\mathrm{MS}^{4}$ fragmentation, as well as by literature search of available chromatographic and MS data.

\subsection{UHPLC-DAD/(-)HESI-MS/MS analysis}

Targeted phenolic compounds were quantified using Dionex Ultimate 3000 UHPLC system (Thermo Fisher Scientific, Bremen, Germany) configured with a triple-quadrupole mass spectrometer (TSQ Quantum Access Max, Thermo Fisher Scientific, Basel, Switzerland) with a heated electrospray ionization (HESI) source. Phenolics in the methanol extract of $S$. verticillata were chromatographically separated on Hypersil gold C18 column $(50 \times 2.1 \mathrm{~mm})$ with $1.9 \mu \mathrm{m}$ particle size (Thermo Fisher Scientific, USA), thermostated at $30^{\circ} \mathrm{C}$. The mobile 
phase, applied with a flow rate of $0.4 \mathrm{~mL} / \mathrm{min}$, consisted of $0.02 \%$ acetic acid in water (A) and LC-MS grade acetonitrile (B). Elution was performed according to Mišić et al. (2015), while the settings of the mass spectrometer were as described in Boroja et al. (2018): vaporizer temperature $350^{\circ} \mathrm{C}$, spray voltage $3510 \mathrm{~V}$, sheet gas $\left(\mathrm{N}_{2}\right)$ pressure $28 \mathrm{AU}$, ion sweep gas pressure $0 \mathrm{AU}$ and auxiliary gas pressure at $4 \mathrm{AU}$, capillary temperature at $270^{\circ} \mathrm{C}$, capillary offset $35 \mathrm{~V}$, and skimmer offset $0 \mathrm{~V}$. Targeted compounds were quantified in a selected reaction monitoring (SRM) mode of the mass spectrometer operated in the negative ionization mode. Collision-induced fragmentation was achieved using argon as the collision gas and collision energy was set to $30 \mathrm{eV}$.

Compounds were quantified by the external standard quantification procedure. Salvianolic acid C, rosmarinic acid hexoside, and methylrosmarinate were quantified relatively, based on the calibration curve of rosmarinic acid, while dicaffeoylquinic acid was quantified using the calibration curve of caffeic acid. Stock standard solutions were prepared by dissolving $1 \mathrm{mg}$ of a pure compound in $1 \mathrm{~mL}$ methanol, and working standard solution was further prepared by mixing the stock solutions of pure compounds in methanol to obtain the concentration of $100 \mu \mathrm{g} / \mathrm{mL}$. Calibration levels in the concentration range from 20 to $0.002 \mu \mathrm{g} / \mathrm{mL}$ were obtained by diluting the working solution with methanol. Determination of the limit of detection (LOD), limit of quantitation (LOQ), linearity, repeatability, and sensitivity of the developed UHPLC-DAD/(-)HESI-MS/MS method was performed. The LOD and LOQ were determined as peak-to-peak values by the signal-to-noise ratios $(\mathrm{S} / \mathrm{N})$, with $\mathrm{S} / \mathrm{N}>3$ for $\mathrm{LOD}$ and $\mathrm{S} / \mathrm{N}>10$ for LOQ. Five replicates of each calibration level were run for LOD and LOQ testing. Regressions of calibration curves showed good linearity with correlation coefficients between $r=0.990$ and $0.999, p<0.001$. The amounts of targeted compounds in the sample were expressed as $\mu \mathrm{g}$ per $100 \mathrm{mg}$ of dry extract ( $\mu \mathrm{g} / 100 \mathrm{mg}$ d.e.).

\subsection{Antimicrobial activity}

\subsubsection{Tested microorganisms}

The bacterial and fungal cultures (ATCC cultures and the clinically isolated strains) were used to evaluate the antimicrobial activity of $S$. verticillata extract. Sixteen microorganisms were tested, eight bacterial and eight fungal strains. In particular, the bacterial strain tested were: Micrococcus lysodeikticus ATCC 4698, Enterococcus faecalis ATCC 29212, Escherichia coli ATCC 25922, Klebsiella pneumoniae ATCC 70063, Pseudomonas aeruginosa ATCC 10145, Bacillus cereus ATCC 10876, Bacillus mycoides FSB 1, and Azobacter chroococcum FSB 14; and the eight fungal strains were: Candida albicans ATCC 10259, Aspergillus brasiliensis ATCC 16404, Fusarium oxysporum FSB 91, Alternaria alternata FSB 51, Aureobasidium pillulans FSB 61, Trichoderma harzianum FSB 12, Penicillium canescens FSB 24, and Doratomyces stemonitis FSB 41. All microbial strains were obtained from the Institute of Public Health Kragujevac, University of Kragujevac, Serbia and Laboratory for Microbiology, Department of Biology, Faculty of Science, University of Kragujevac, Kragujevac, Serbia. The bacteria and fungi cultures were stored at $4^{\circ} \mathrm{C}$ and subcultured once a month. Bacterial strains were cultured overnight at $37^{\circ} \mathrm{C}$ in nutrient agar (NA) and fungi were cultured on Sabouraud dextrose agar (SDA) and potato glucose agar (PDA) at $28^{\circ} \mathrm{C}$ for 3 days.

\subsubsection{Antibacterial activity tests}

The minimum inhibitory concentration (MIC) of SV extract against tested microorganisms was determined based on the microdilution method in 96 multi-well microtiter plates (Sarker et al., 2007), with some modifications. All tests were performed in Müller-Hinton broth (MHB). Briefly, a fresh overnight culture of bacteria was suspended in sterile $0.85 \%$ saline $(8.5 \mathrm{~g} / \mathrm{L} \mathrm{NaCl})$ and adjusted by the colorimeter to a concentration of $5 \times 10^{6} \mathrm{CFU} / \mathrm{mL}$ (colony-forming units per milliliter) (CLSI, 2012). Different solvent dilutions of plant extract were dissolved in $5 \%$ dimethyl sulfoxide (DMSO) in sterile water and added to over the wells containing $50 \mu \mathrm{L}$ of $\mathrm{MHB}$; then, $10 \mu \mathrm{L}$ of resazurin indicator solution $(6.25 \mathrm{mg} / \mathrm{mL}$ in sterile distilled water) and $30 \mu \mathrm{L}$ of MHB were added to each well. Finally, $10 \mu \mathrm{L}$ of bacterial colony suspension was added to all the wells. The final bacterial concentration of in each well was $5 \times 10^{5} \mathrm{CFU} / \mathrm{mL}$ (CLSI, 2012). For each strain, the growth conditions and the sterility of the medium were checked. Standard antibiotic chloramphenicol was used to control the sensitivity of the tested bacteria. The microplates were incubated for $24 \mathrm{~h}$ at $37^{\circ} \mathrm{C}$. Any color change of the indicator from purple to pink or colorless was recorded as positive. The lowest concentration that produced a significant inhibition of the growth of the bacteria in comparison with the positive control was identified as the MIC.

\subsubsection{Antifungal activity tests}

The fungal colonies were washed from the surface of agar plates with sterile $0.85 \%$ saline and the inoculum suspension was adjusted to a concentration of $5 \times 10^{4} \mathrm{CFU} / \mathrm{mL}$ according to NCCLS recommendation (NCCLS, 2002a,b). Identically, the 2-fold serial microdilution method was used for determination of MIC. The test was performed on Sabouraud dextrose broth (SDB). The SV extract $(50 \mu \mathrm{L})$ was dissolved in sterile water to obtain a concentration of $40 \mathrm{mg} / \mathrm{mL}$, added into the first row of the plate and double dilutions were made in all the other rows that were filled with $50 \mu \mathrm{L}$ of SDB. Thereafter, $10 \mu \mathrm{L}$ of SDB was added in all wells followed by addition of fungal inoculum suspension. For each strain, the growth conditions and the sterility of the medium were checked. Nystatin was used as the control against the tested fungi. Plates were placed in an incubator at $28^{\circ} \mathrm{C}$ for $48 \mathrm{~h}$. The lowest concentrations without visible growth of fungi were defined as MICs.

\subsection{Antioxidant activity}

\subsubsection{Total antioxidant capacity}

The total antioxidant capacity of SV (Prieto et al., 1999) was monitored by the formation of a green phosphate/Mo (V) complex at acid $\mathrm{pH}$. In $0.3 \mathrm{~mL}$ of extract solution $(0.5 \mathrm{mg} / \mathrm{mL})$ was added $3 \mathrm{~mL}$ of reagent solution $(0.6 \mathrm{M}$ sulfuric acid, $28 \mathrm{mM}$ sodium phosphate and $4 \mathrm{mM}$ ammonium molybdate). Then, the mixtures were incubated at $95^{\circ} \mathrm{C}$ for $90 \mathrm{~min}$. After cooling to room temperature, the absorbance of the solution was measured at $695 \mathrm{~nm}$. The total antioxidant capacity is expressed as ascorbic acid equivalents (mg AA/g).

\subsubsection{2,2-Diphenyl-1-picrylhydrazyl (DPPH) free-radical scavenging activity}

To determine scavenging DPPH radical activity different concentrations of SV in methanol ( $2 \mathrm{~mL}$, eight double dilutions from $2 \mathrm{mg}$ / $\mathrm{mL})$ were mixed with the same volume of DPPH solution $(80 \mu \mathrm{g} / \mathrm{mL})$ (Kumarasamy et al., 2007). After $30 \mathrm{~min}$ of incubation at room temperature, the absorbance was measured at $517 \mathrm{~nm}$. Ascorbic acid (AA) and butylated hydroxytoluene (BHT) were used as reference standards. The DPPH free-radical scavenging activity (\%) was calculated with the following equation [Eq. 1]:

((1)) \% radical scavenging activity $=\left[\left(\mathrm{A}_{\text {control }}-\mathrm{A}_{\text {sample }}\right) / \mathrm{A}_{\text {control }}\right] \times$ 100

where $\mathrm{A}_{\text {control }}$ is the absorbance of the DPPH radical in methanol and A sample is the absorbance of the samples. The $\mathrm{IC}_{50}$ value, which is the concentration of the test material that reduces $50 \%$ of the free-radical concentration, was calculated as $\mu \mathrm{g} / \mathrm{mL}$ through a sigmoidal dose-response curve.

2.7.3. 2,2'-Azinobis-(3-ethylbenzothiazoline-6-sulfonic acid) diammonium (ABTS) radical-cation scavenging activity

The ABTS radical cation scavenging activity was estimated by the method described by Re et al. (1999). The radical cation $\left(\right.$ ABTS $\left.^{+}\right)$was generated by reacting $7 \mathrm{mM}$ stock solution of ABTS (2,2'-azinobis-(3- 
ethylbenzothiazoline-6-sulfonic acid) diammonium salt) with $2.45 \mathrm{mM}$ potassium persulfate and the mixture was left to stand in the dark at room temperature for $16 \mathrm{~h}$ before use. The $\mathrm{ABTS}^{+}$solution was diluted with $5 \mathrm{mM}$ phosphate-buffered saline ( $\mathrm{pH} 7.4)$ to rich the absorbance of $0.70 \pm 0.02$ at $734 \mathrm{~nm}$. After $30 \mathrm{~min}$ from the addition of $100 \mu \mathrm{L}$ of sample to $900 \mu \mathrm{L}$ of $\mathrm{ABTS}^{+}$solution, the absorbance was measured at $734 \mathrm{~nm}$. Two compounds, AA and BHT, were used as reference antioxidants. A control sample was prepared to contain the same volume without test compounds or reference antioxidants. The percent of $\mathrm{ABTS}^{+}$scavenging activity of the samples was calculated using a previous equation [Eq. 1 ] and $\mathrm{IC}_{50}$ values were expressed as previous using a sigmoidal dose-response curve.

\subsubsection{Nitric oxide radical scavenging activity}

Nitric oxide radical (NO) scavenging capacity was measured using the Griess reaction, according to the method described by Green et al. (1982). The samples $(0.5 \mathrm{~mL}$ of SV or reference antioxidants AA and BHT) at different concentrations were mixed with the same volume of $5 \mathrm{mM}$ sodium nitroprusside dissolved in $0.01 \mathrm{M}$ phosphate-buffered saline ( $\mathrm{NaCl} 0.138 \mathrm{M} ; \mathrm{KCl} 0.0027 \mathrm{M}, \mathrm{pH}$ 7.4). Incubation was performed at $25^{\circ} \mathrm{C}$ for $2.5 \mathrm{~h}$, and after that $1 \mathrm{~mL}$ of Griess reagent (1\% sulphanilamide, $2 \%$ orthophosphoric acid, and $0.1 \% \mathrm{~N}$-(1-naphthyl)ethylenediamine dihydrochloride) was added to the mixture. After an additional incubation at $25^{\circ} \mathrm{C}$ for $30 \mathrm{~min}$, the absorbance of the solution was measured at $546 \mathrm{~nm}$. The results of nitric oxide radical scavenging activity were expressed as $\mathrm{IC}_{50}$.

\subsubsection{Determination of the inhibitory activity toward lipid peroxidation}

The thiocyanate method (Hsu et al., 2008) was used to determine the antioxidant activity of SV extract in an oil-in-water emulsion. The extract or reference compounds $(0.5 \mathrm{~mL}$; SV, AA, and BHT) were added to linoleic acid emulsion $(2.5 \mathrm{~mL} ; 0.2804 \mathrm{~g}$ linoleic acid, $0.2804 \mathrm{~g}$ Tween-80 as an emulsifier in $50 \mathrm{~mL} 40 \mathrm{mM}$ phosphate buffer, $\mathrm{pH} 7.0$ ) and the mixture was homogenized. The final volume was adjusted to $5 \mathrm{~mL}$ with phosphate buffer $(40 \mathrm{mM}, \mathrm{pH} 7.0)$. After incubation at $37^{\circ} \mathrm{C}$ in the dark for $72 \mathrm{~h}$, a $0.1 \mathrm{~mL}$ aliquot of the reaction solution was mixed with methanol $(4.7 \mathrm{~mL}, 75 \%), \mathrm{FeSO}_{4}(0.1 \mathrm{~mL}, 20 \mathrm{mM})$, and ammonium thiocyanate $(0.1 \mathrm{~mL}, 30 \%)$. The absorbance of this mixture was measured at $500 \mathrm{~nm}$, after $3 \mathrm{~min}$ of stirring. Inhibition percent of linoleic acid peroxidation was calculated using the following equation [Eq. 2]:

$\%$ inhibition $=\left[\left(\mathrm{A}_{\text {control }}-\mathrm{A}_{\text {sample }}\right) / \mathrm{A}_{\text {control }}\right] \times 100$

where $\mathrm{A}_{\text {control }}$ is the absorbance of the control and $\mathrm{A}_{\text {sample }}$ is the absorbance of the samples. The $\mathrm{IC}_{50}$ values were calculated as $\mu \mathrm{g} / \mathrm{mL}$ through a sigmoidal dose-response curve.

\subsubsection{Measurement of ferrous ion chelating ability}

The ferrous ion chelating activity of SV extract was measured by the decrease in absorbance at $562 \mathrm{~nm}$ of the iron (II)-ferrozine complex (Yan et al., 2006). Iron (II) sulfate ( $1 \mathrm{~mL}, 0.125 \mathrm{mM} \mathrm{FeSO}_{4}$ ) was added to $1 \mathrm{~mL}$ sample (with different dilutions), followed by ferrozine ( $1 \mathrm{~mL}$, $0.3125 \mathrm{mM}$ ). After $10 \mathrm{~min}$ the absorbances of the mixtures were measured. AA and BHT were used as standards. The ability of the sample to chelate ferrous ion was calculated relative to the control (consisting of iron and ferrozine only) using the equation [Eq. 3]:

$\%$ chelating effect $\left[\left(\mathrm{A}_{\text {control }}-\mathrm{A}_{\text {sample }}\right) / \mathrm{A}_{\text {control }}\right] \times 100$

where $\mathrm{A}_{\text {control }}$ is the absorbance of the control and $\mathrm{A}_{\text {sample }}$ is the absorbance of the samples. The $\mathrm{IC}_{50}$ values were calculated as previous using a sigmoidal dose-response curve.

\subsection{Biocompatibility analysis}

Murine BALBC-3T3 (fibroblasts), human A431 (epidermoid carcinoma), HepG2 (hepatic carcinoma), and LoVo (colorectal adenocarcinoma) cells were obtained from ATCC, whereas HaCaT (primary epidermal keratinocyte) cells were from AddexBio (San Diego, CA, USA). All cells were cultured in Dulbecco's modified Eagle's medium (DMEM) (Sigma-Aldrich, St Louis, MO, USA), supplemented with $10 \%$ fetal bovine serum (HyClone), $2 \mathrm{mM}$ L-glutamine and antibiotics, all from Sigma-Aldrich, under a $5 \% \mathrm{CO}_{2}$ humidified atmosphere at $37^{\circ} \mathrm{C}$. For toxicity experiments, cells were seeded in 96-well plates at a density of $2.5 \times 10^{3}$ cells per well. Twenty-four hours after seeding, increasing concentrations of SV extract were added to the cells $(5-50 \mu \mathrm{g} / \mathrm{mL})$. Cell viability was assessed by the MTT (3-(4,5-dimethylthiazol-2-yl)-2,5diphenyltetrazolium bromide) assay after $48-72 \mathrm{~h}$, as described by Petruk et al. (2016).

\subsection{Statistical analysis}

The data are expressed as the mean \pm standard deviation (SD). The $\mathrm{IC}_{50}$ for in vitro antioxidant potential was calculated using nonlinear regression analysis from the sigmoidal dose-response inhibition curve using OriginPro 8 Software. For statistical analyses of the data, the analysis of variance (ANOVA) was applied and the group means were compared with the least significant difference test (LSD). The results were considered statistically significant at $p<0.05$.

\section{Results}

\subsection{Phytochemical composition of $S$. verticillata extract}

The spectrophotometrically measured contents of total phenolic compounds, along with total flavonoids, flavonols, and phenolic acids in SV extract are shown in Table 1. Data indicated a high content in total phenolics in aerial parts of $S$. verticillata, with flavonoids (244.4 mg QU/g d.e.) and phenolic acids ( $41.9 \mathrm{mg} \mathrm{CA} / \mathrm{g}$ d.e.) as the most abundant phytochemicals.

The qualitative evaluation of phenolic compounds in methanol extract of $S$. verticillata aerial parts was performed using high resolution mass spectrometry (HRMS) in combination with $\mathrm{MS}^{4}$ fragmentation. The obtained UHPLC-MS ${ }^{4}$ Orbitrap metabolic fingerprinting data of SV extract resulted in the detection of totally 29 phenolic compounds (Table 2) and the corresponding base peak chromatogram is depicted in Fig. 1. The identified compounds can be divided into two structurally different groups: 1) phenolic acids and their derivatives (21 compounds) and 2) flavonoids and their derivatives (8 compounds). Among all identified compounds, eight were confirmed using available standards, while the others were identified using HRMS technique (exact mass search of their deprotonated molecule $[\mathrm{M}-\mathrm{H}]^{-}$) and $\mathrm{MS}^{2}, \mathrm{MS}^{3}$, and $\mathrm{MS}^{4}$ fragmentation behavior, as well as the comparison with the available literature. The peak numbers, retention times $\left(t_{R}, \mathrm{~min}\right)$, compound names, molecular formulas, calculated and exact masses $\left([\mathrm{M}-\mathrm{H}]^{-}, m / z\right)$, mean mass accuracy errors (ppm), as well as major $\mathrm{MS}^{2}, \mathrm{MS}^{3}$ and $\mathrm{MS}^{4}$ fragment ions of phenolics founds in SV extracts are summarized in Table 2.

Table 1

Total phenolic compounds, flavonoids, flavonols, and phenolic acids in S. verticillata aerial part extract (SV).

\begin{tabular}{lllll}
\hline Extract & Total phenolic compounds (mg GA/g d.e.) & Total flavonoids (mg QU/g d.e.) & Total flavonols (mg RU/g d.e.) & Total phenolic acids (mg CA/g d.e.) \\
\hline $\mathrm{SV}$ & $175.6 \pm 16.3$ & $244.4 \pm 4.7$ & $16.9 \pm 0.8$ & $41.9 \pm 5.4$ \\
\hline
\end{tabular}

GA - gallic acid equivalents, QU - quercetin equivalents, RU - rutin equivalents, CA - caffeic acid equivalents, d.e. - dry weight of the extract. 


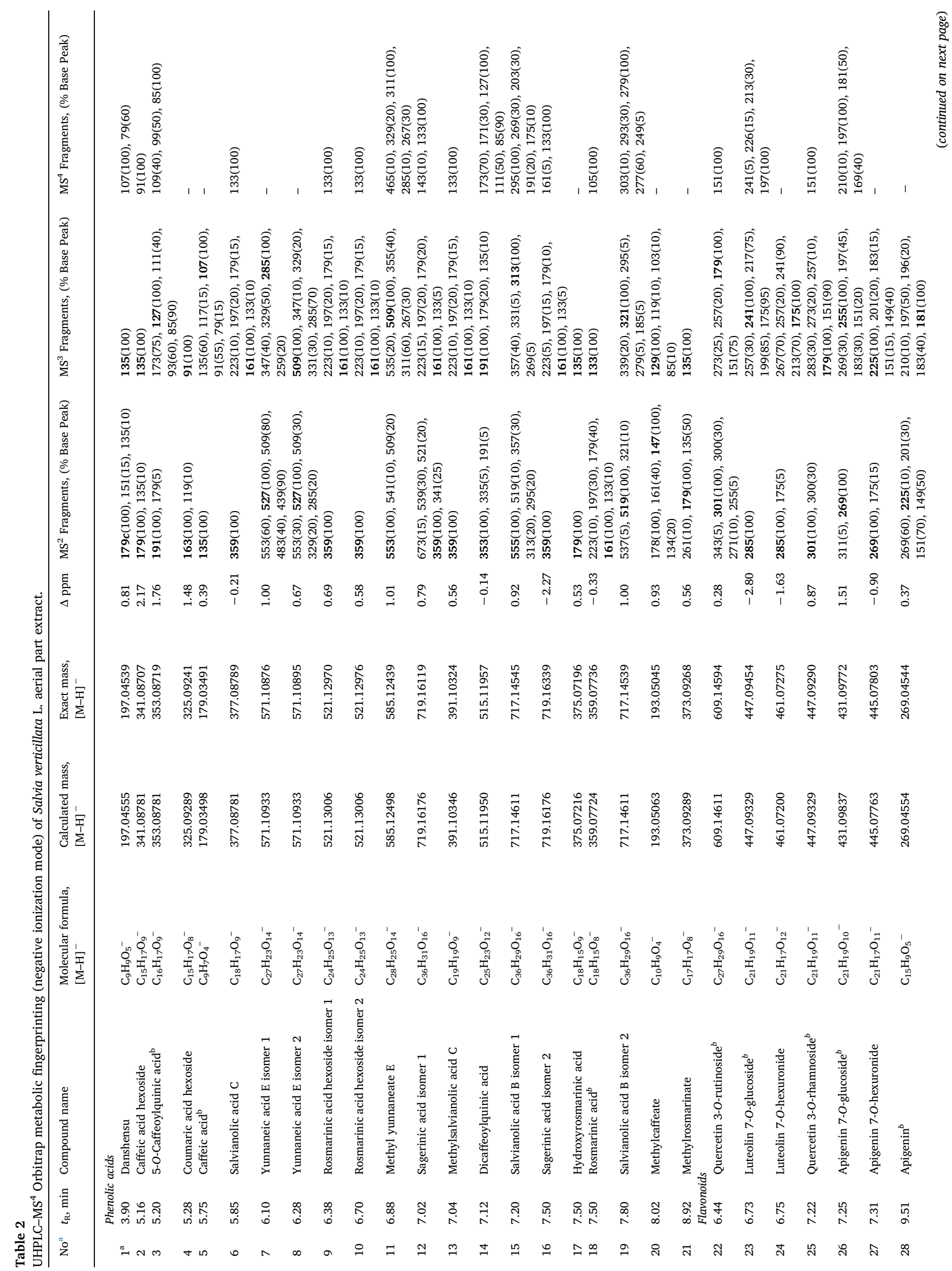


The examination of mass spectra of phenolic acids and their derivatives revealed various caffeic acid derivatives, which were expected (Li et al., 2015). More specifically, from phenolic acids group, only one identified compound is not a caffeic acid derivative and it is a coumaric acid hexoside (compound 4). This compound eluting at $5.28 \mathrm{~min}$ and showing $\left([\mathrm{M}-\mathrm{H}]^{-}\right)$at $m / z 325$, gave $\mathrm{MS}^{2}$ base peak at $m / z 163$ (mass of deprotonated coumaric acid) and secondary $\mathrm{MS}^{2}$ peak at $119 \mathrm{~m} / \mathrm{z}$ which was obtained by further loss of $\mathrm{CO}_{2}$ group (44 Da). As for the other phenolic acid derivatives, they all showed specific fragments of residues of caffeic acid. For example, compound 14(dicaffeoylqiunic acid, eluting at $7.12 \mathrm{~min}$ and showing $[\mathrm{M}-\mathrm{H}]^{-}$at $m / z 515$ ) showed $\mathrm{MS}^{2}$ base peak at $m / z 353$ (loss of caffeoyl moiety) and $\mathrm{MS}^{3}$ base peak at $m / z$ 191 which corresponds to deprotonated quinic acid (Table 2).

Eight compounds from the group of flavonoids (quercetin 3-O-rutinoside, luteolin 7-O-glucoside, quercetin 3-O-rhamnoside, apigenin 7$O$-glucoside, and apigenin) were identified in the SV extract and presence of five of them was confirmed by comparison with appropriate standards. Luteolin 7-O-hexuronide (compound 24) and apigenin 7-Ohexuronide (compound 27) were identified by a specific fragment at $175 \mathrm{~m} / \mathrm{z}$, which corresponds to deprotonated hexuronic acid. Presence of luteolin and apigenin as aglycones was confirmed by specific $\mathrm{MS}^{3}$ fragmentation in both cases. These two hexuronyl derivatives were already identified in some Salvia species (Šulniūte et al., 2017). Cirsimaritin (compound 29), known to be present in $S$. verticillata (Ulubelen and Topcu, 1984) was visible as pseudomolecular ion $[\mathrm{M}-\mathrm{H}]^{-}$at $m / z$ 313 and was eluted at $10.92 \mathrm{~min}$. It produced the $\mathrm{MS}^{2}$ base peak at $\mathrm{m} / \mathrm{z}$ 298 (generated by the loss of $\mathrm{CH}_{3}$ group $-15 \mathrm{Da}$ ) and $\mathrm{MS}^{3}$ base peak at $\mathrm{m} / z 269$ (loss of second $\mathrm{CH}_{3}$ group). The $\mathrm{MS}^{4}$ base peak resulting from a further loss of CO group (28 Da) was identified at $\mathrm{m} / z 255$. Proposed fragmentation pathway of this compound is depicted in Fig. S1.

UHPLC-DAD/(-)HESI-MS/MS analysis was targeted towards totally 14 compounds belonging to the phenolics (12 compounds) and phenolic diterpenes ( 2 compounds). The quantitative data of targeted phenolic compounds in SV extract (expressed in $\mu \mathrm{g}$ per $100 \mathrm{mg}$ of dry extract) are presented in Table 3. The most abundant compound in SV was rosmarinic acid $(235 \mathrm{mg} / \mathrm{g}$ d.e.), along with salvianolic acid C $(1.1 \mathrm{mg} / \mathrm{g}$ d.e.). Their concentration in the extract was approximately more than a dozen times higher than those of the other quantified polyphenolics. Also, a high concentration of several rosmarinic acid derivatives, i.e., rosmarinic acid hexoside and methylrosmarinate (3.6 and $1.07 \mathrm{mg} / \mathrm{g}$ d.e., respectively) was found in SV extract. Salvianolic acid B was present in SV in much lower amount $(470 \mu \mathrm{g} / \mathrm{g}$ d.e. $)$ compared with salvianolic acid C. The aerial parts of $S$. verticillata had moderate amounts of caffeic acid and its' derivatives with quinic acid. Flavonoids (quercetin, rutin, quercitrin, apigenin, and apigenin-7-Oglucoside) and characteristic diterpenes (carnosol and carnosic acid) were also present in SV in lower concentrations.

\subsection{Biocompatibility and cytotoxicity of S. verticillata extract}

The biocompatibility of $S$. verticillata aerial part extract was first assessed by using a cell survival assay. SV extract was tested on a panel of eukaryotic cell lines, from immortalized murine BalbC-3T3 fibroblasts and human normal HaCaT keratinocytes to human cancer cells: epidermoid carcinoma (A431), liver cancer (HepG2), and colon carcinoma (LoVo). Cells were treated for 48 and $72 \mathrm{~h}$ with an increasing amount of SV extract (from 5 to $50 \mu \mathrm{g} / \mathrm{mL}$ ) and cell viability was assessed by the MTT assay. As shown in Fig. 2, no toxicity of SV extract was observed on any cell line analyzed after $48 \mathrm{~h}$ incubation. After $72 \mathrm{~h}$ incubation, the extract did not affect cell viability on immortalized cells, however a very slight, but significant, decrease in the viability of LoVo cancer cells was found after $72 \mathrm{~h}$ incubation only at the highest concentration used. These results indicate that SV extract is full biocompatible with eukaryotic cells. 


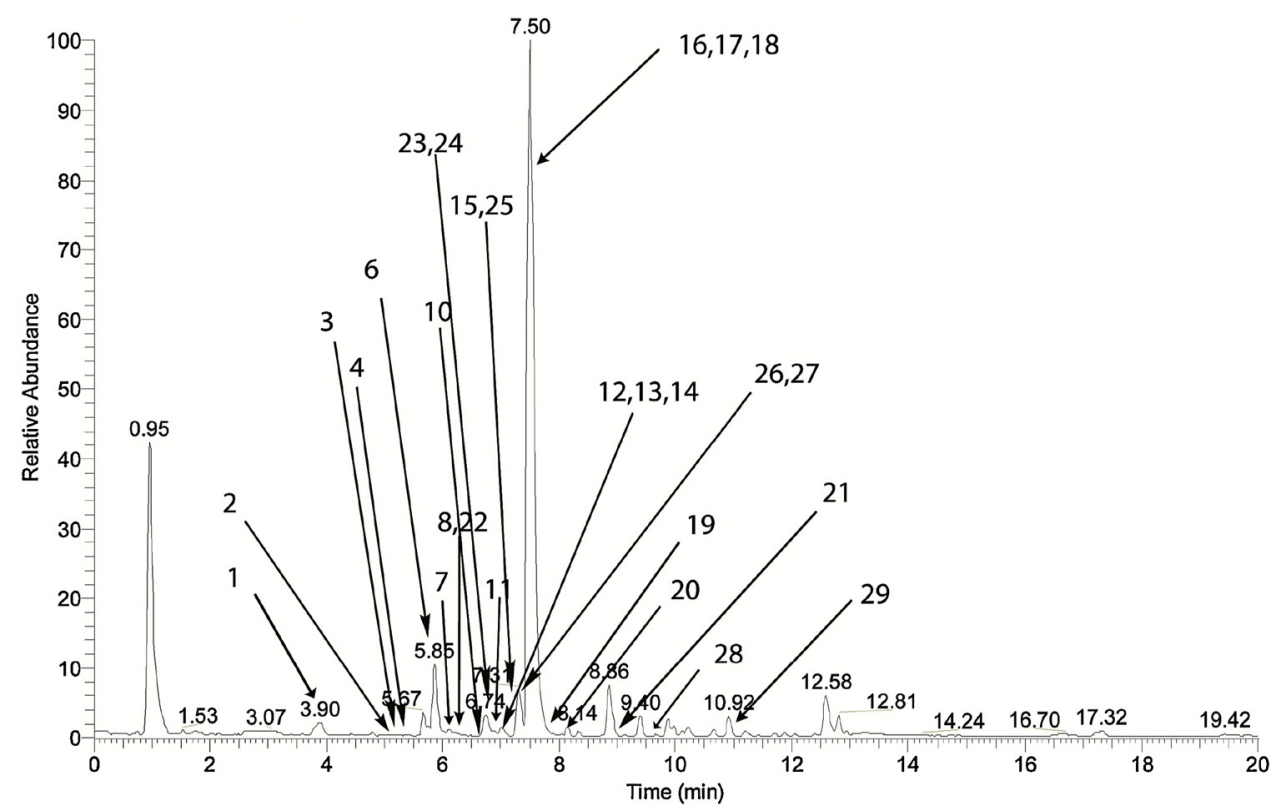

Fig. 1. UHPLC-MS ${ }^{4}$ Orbitrap chromatogram (negative ionization mode) of $S$. verticillata aerial part extract. Peak numbers are as indicated in Table 2.

\subsection{Bioactivity of S. verticillata extract}

To explore the possibility to use SV extract as a source of the bioactive molecule(s), the extract was tested for its antibacterial and antifungal effects, as well as for its antioxidant activity in vitro. The antibacterial potential of SV, reported in Table 4, clearly indicated that this extract was very active on $B$. cereus, as it was able to inhibit the growth of this strain at a concentration of $1.25 \mathrm{mg} / \mathrm{mL}$. On the other hand, the extract was less active on the other bacterial species tested (as indicated by higher MIC values). As for antifungal activity, the lowest MIC value was found on $P$. canescens $(5 \mathrm{mg} / \mathrm{mL})$, then $C$. albicans and $F$. oxysporum (10 and $20 \mathrm{mg} / \mathrm{mL}$, respectively), while the extract had no antifungal potential on other treated fungal species (MIC $>20 \mathrm{mg}$ / $\mathrm{mL}$ ). Compared with the positive control used, i.e., the commercial antibiotic chloramphenicol and the antimycotic nystatin, SV extract had moderate activity.

Then, the antioxidant activity of SV extract was evaluated, by using six different in vitro assays. The results of the experiments are shown in Table 5. SV extract exerted a very good antioxidant activity, in some cases comparable with the reference antioxidants used (ascorbic acid and BHT). The total antioxidant capacity of $1 \mathrm{~g}$ SV was in the range of $255 \mathrm{mg}$ of ascorbic acid activity. The scavenging potential of SV towards DPPH radicals $\left(\mathrm{IC}_{50} 33.04 \mu \mathrm{g} / \mathrm{mL}\right.$ ) was much lower than ascorbic acid, but comparable with that of BHT (IC I $_{50} 26.11 \mu \mathrm{g} / \mathrm{mL}, p<$ 0.05). The ABTS ${ }^{+}$scavenging results indicated that SV extract had a pronounced activity $\left(\mathrm{IC}_{50} 67.01 \mu \mathrm{g} / \mathrm{mL}\right.$ ), but around three and two times lower, compared with ascorbic acid and BHT (15.43 and $37.18 \mu \mathrm{g} / \mathrm{mL}$, respectively). NO radical scavenging potential of SV was comparable with ascorbic acid activity $\left(\right.$ IC $_{50} 73.12$ and $50.56 \mu \mathrm{g} / \mathrm{mL}$, respectively), given that BHT was not active at the highest concentration tested. BHT was able to markedly inhibit lipid peroxidation in linoleic acid emulsion ( $\mathrm{IC}_{50}$ value $3.82 \mu \mathrm{g} / \mathrm{mL}$ ), while SV had moderate activity ( $\mathrm{IC}_{50} 58.07 \mu \mathrm{g} / \mathrm{mL}$ ) and ascorbic acid had no effects at the highest concentration applied. All tested samples did not exert metal chelating effects.

\section{Discussion}

In very few previous studies addressing the phytochemical characterization of $S$. verticillata extracts, caffeic acid and its derivatives were the main identified compounds (Fig. 3), with rosmarinic acid being the most abundant bioactive metabolite (Öztürk et al., 2011; Šulniūtè et al., 2017; Tepe et al., 2007), according to our results. Caffeic acid has an essential role in the biosynthesis of secondary metabolites of

Table 3

UHPLC/ $(-)$ HESI-MS/MS quantitative data of targeted phenolic compounds in $S$. verticillata aerial part methanol extract. Concentration is presented as $\mu \mathrm{g}$ per $100 \mathrm{mg}$ of dry extract $[\mu \mathrm{g} / 100 \mathrm{mg}$ d.e.]. Values are means of three replicates $\pm \mathrm{SD}$.

\begin{tabular}{|c|c|c|c|c|c|}
\hline No. & Rt (min) & Compounds & {$[\mathrm{M}-\mathrm{H}]^{-}$} & Diagnostic $\mathrm{MS}^{2}$ fragments $[\mathrm{M}-\mathrm{H}]^{-}$ & Concentration $[\mu \mathrm{g} / 100 \mathrm{mg}$ d.e. $]$ \\
\hline 1 & 1.80 & 5-O-Caffeoylquinic acid ${ }^{\mathrm{s}}$ & 353 & $127 ; 191$ & $145.303 \pm 22.461$ \\
\hline 2 & 2.45 & Caffeic acid ${ }^{\mathrm{s}}$ & 179 & $134 ; 135$ & $9.539 \pm 2.054$ \\
\hline 3 & 3.17 & Salvianolic acid C & 377 & $161 ; 359$ & $1115.486 \pm 19.941$ \\
\hline 4 & 3.92 & Quercetin 3-O-rutinoside $^{\mathrm{s}}$ & 609 & $301 ; 179$ & $0.262 \pm 0.031$ \\
\hline 5 & 4.14 & Rosmarinic acid hexoside & 521 & $161 ; 359$ & $359.519 \pm 20.830$ \\
\hline 6 & 4.38 & Dicaffeoylquinic acid & 515 & $135 ; 191$ & $35.981 \pm 1.062$ \\
\hline 7 & 4.55 & Quercetin 3-O-rhamnoside ${ }^{\mathrm{s}}$ & 447 & $201 ; 300$ & $0.013 \pm 0.007$ \\
\hline 8 & 4.55 & Apigenin-7-O-glucoside ${ }^{\mathrm{s}}$ & 431 & $269 ; 311$ & $7.964 \pm 0.274$ \\
\hline 9 & 4.58 & Rosmarinic acid ${ }^{s}$ & 359 & $133 ; 161$ & $23458.624 \pm 521.508$ \\
\hline 10 & 5.10 & Salvianolic acid $\mathrm{B}^{\mathrm{s}}$ & 717 & $321 ; 519$ & $46.980 \pm 1.055$ \\
\hline 11 & 5.72 & Methylrosmarinate & 373 & $135 ; 179$ & $107.425 \pm 2.690$ \\
\hline 12 & 5.88 & Apigenin ${ }^{\mathrm{s}}$ & 269 & $117 ; 149$ & $0.676 \pm 0.032$ \\
\hline 13 & 7.70 & Carnosol $^{\mathrm{s}}$ & 329 & $201 ; 285$ & $0.257 \pm 0.002$ \\
\hline 14 & 9.86 & Carnosic acid ${ }^{s}$ & 331 & $244 ; 287$ & $0.169 \pm 0.011$ \\
\hline
\end{tabular}

$\mathrm{s}$ Identified according to the standards. 

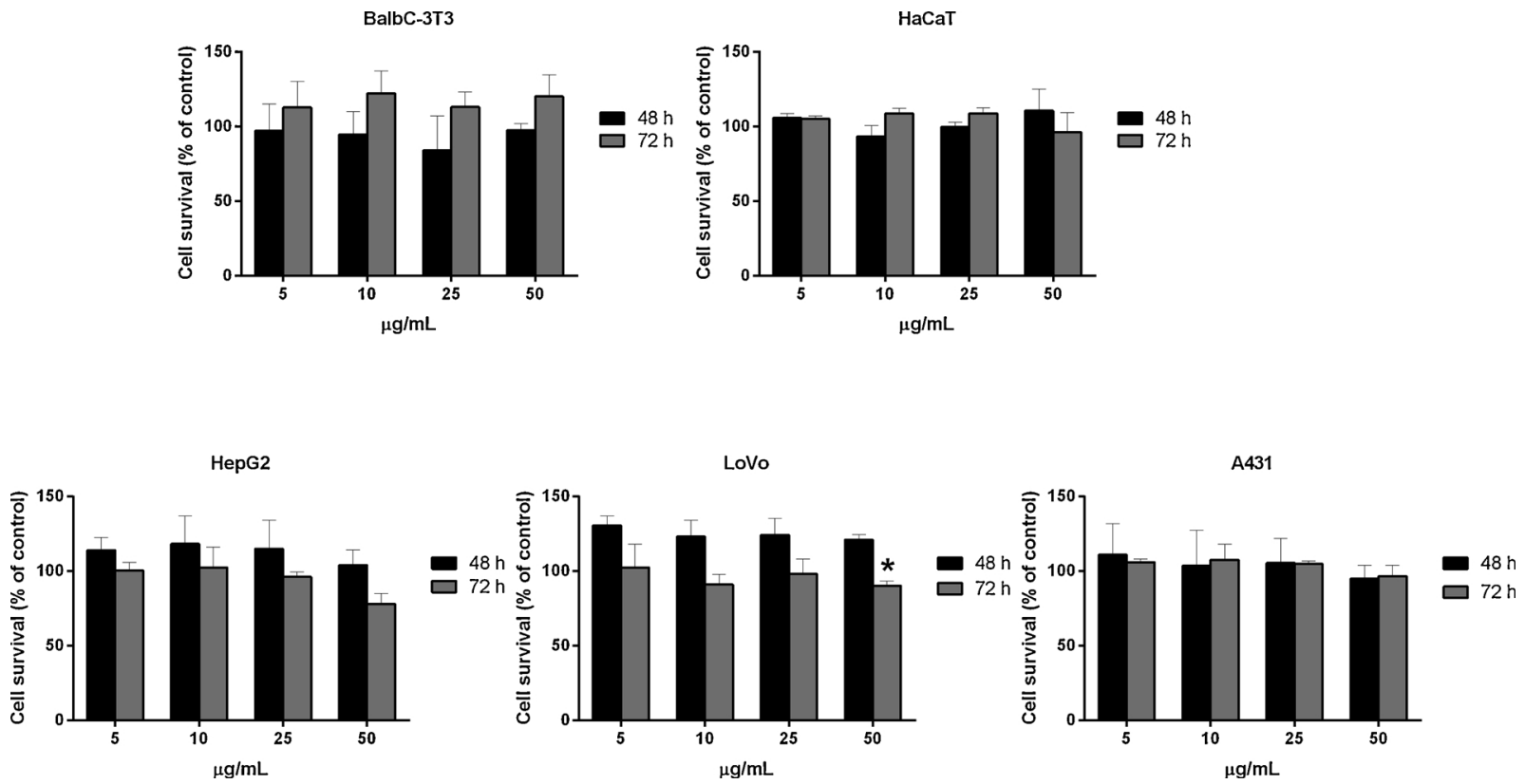

Fig. 2. Biocompatibility of the $S$. verticillata extract (SV) on BalbC-3T3, HaCaT, A431, HepG2, and LoVo cell lines. Dose- and time-response curves of cells after 48 and $72 \mathrm{~h}$ of incubation in the presence of $5,10,25$, and $50 \mu \mathrm{g} / \mathrm{mL}$ of the extract. Values are given as means $\pm \mathrm{SD}(\mathrm{n} \geq 3)$. * indicated $p<0.05$ with respect to untreated cells.

Table 4

Antibacterial and antifungal activity of $S$. verticillata methanolic extract.

\begin{tabular}{|c|c|c|c|c|}
\hline \multicolumn{2}{|l|}{ Bacterial species } & \multicolumn{3}{|l|}{$\mathrm{MIC}^{*}$} \\
\hline & & S. verticillata & \multicolumn{2}{|c|}{ Chloramphenicol } \\
\hline Micrococcus lysodeikticus & ATCC 4698 & 10 & & \\
\hline Enterococcus faecalis & ATCC 29212 & 20 & 1 & \\
\hline Escherichia coli & ATCC 25922 & 20 & & \\
\hline Klebsiella pneumoniae & ATCC 70063 & 20 & & \\
\hline Pseudomonas aeruginosa & ATCC 10145 & 20 & 4 & \\
\hline Bacillus cereus & ATCC 10876 & 1.25 & & \\
\hline Bacillus mycoides & FSB 1 & 10 & 1 & \\
\hline Azobacter chroococcum & FSB 14 & 10 & 1 & \\
\hline \multicolumn{2}{|l|}{ Fungal species } & \multicolumn{3}{|l|}{ MIC } \\
\hline & & \multicolumn{2}{|c|}{ S. verticillata } & Nystatin \\
\hline Candida albicans & ATCC 10259 & \multicolumn{2}{|c|}{10} & 5 \\
\hline Aspergillus brasiliensis & ATCC 16404 & \multicolumn{2}{|l|}{$>20$} & 40 \\
\hline Fusarium oxysporum & FSB 91 & \multicolumn{2}{|l|}{20} & 20 \\
\hline Alternaria alternata & FSB 51 & \multicolumn{2}{|l|}{$>20$} & 40 \\
\hline Aureobasidium pillulans & FSB 61 & \multicolumn{2}{|l|}{$>20$} & $>40$ \\
\hline Trichoderma harzianum & FSB 12 & \multicolumn{2}{|l|}{$>20$} & $>40$ \\
\hline Penicillium canescens & FSB 24 & \multicolumn{2}{|l|}{5} & 10 \\
\hline Doratomyces stemonitis & FSB 41 & \multicolumn{2}{|l|}{$>20$} & $>40$ \\
\hline
\end{tabular}

* MIC - minimum inhibitory concentration values given as $\mathrm{mg} / \mathrm{mL}$ for plant extracts and as $\mu \mathrm{g} / \mathrm{mL}$ for antibiotic (Chloramphenicol) and antimycotic (Nystatin). the Lamiaceae family and exists principally in its dimeric form: rosmarinic acid (Lu and Yeap Foo, 2002). Nevertheless, many other derivatives of caffeic acid were detected in our study on $S$. verticillata monomers, such as danshensu and dimers like salvianolic acid B (or lithospermic acid B). Other salvianolic acids dimers (G, F), normally present in Salvia plants, were not detected in our study. Usually, caffeic acid trimers, generally represent the largest group of metabolites in the genus Salvia (Lu and Yeap Foo, 2002); accordingly, in SV extract a quite high contents of salvianolic acid C (most likely obtained by conversion of unstable salvianolic acid A) and yunnaneic acid $\mathrm{E}$ (from oxidation of yunnaneic acid C) were detected. A representative of tetramers derived from caffeic acid, sagerinic acid, was also found in aerial parts of $S$. verticillata. Besides phenolic acids derived from caffeic acid, the SV extract was rich in other polyphenolic compounds, like flavones, flavonols and their glycosides, which are also widely distributed constituents in genus Salvia (Lu and Yeap Foo, 2002; Wu et al., 2012). In the analyzed SV extract, apigenin and 7-O-derivatives of apigenin and luteolin were detected, along with 3-O-derivatives of quercetin (rutin and quercitrin) and cirismaritin (6- hydroxyapigenin-6,7-dimethyl ether), which are all typical flavonoids of Salvia plants (Lu and Yeap Foo, 2002). However, the amount of analyzed flavonoids was much lower compared with phenolic acids. Similar results on the phytochemical composition of $S$. verticillata were recently reported by Šulniūte et al. (2017). Also, Zengin et al. (2018) showed that S. verticillata subsp. amasiaca contained most of those compounds, claiming

Table 5

Antioxidant activity of $S$. verticillata methanolic extract.

\begin{tabular}{|c|c|c|c|c|c|c|}
\hline \multirow{2}{*}{$\begin{array}{l}\text { Sample and } \\
\text { standards }\end{array}$} & \multirow{2}{*}{$\begin{array}{l}\text { Total antioxidant activity } \\
\text { (mg AA/g) }\end{array}$} & \multicolumn{5}{|l|}{$\mathrm{IC}_{50}$ values* $(\mu \mathrm{g} / \mathrm{mL})$} \\
\hline & & $\begin{array}{l}\text { DPPH radical } \\
\text { scavenging activity }\end{array}$ & $\begin{array}{l}\text { ABTS radical-cation } \\
\text { scavenging activity }\end{array}$ & $\begin{array}{l}\text { NO radical scavenging } \\
\text { activity }\end{array}$ & $\begin{array}{l}\text { Inhibitory activity toward } \\
\text { lipid peroxidation }\end{array}$ & $\begin{array}{l}\text { Metal chelating } \\
\text { activity }\end{array}$ \\
\hline S. verticillata & $254.55 \pm 17.75$ & $33.04 \pm 5.83^{\mathrm{a}}$ & $67.01 \pm 13.62^{\mathrm{a}}$ & $73.12 \pm 19.04$ & $58.07 \pm 9.72$ & $>4000$ \\
\hline Ascorbic acid & - & $5.69 \pm 0.82^{b}$ & $15.43 \pm 2.65^{\mathrm{b}}$ & $50.56 \pm 20.69$ & $>100$ & $>100$ \\
\hline BHT & - & $26.11 \pm 2.58^{\mathrm{a}}$ & $37.18 \pm 4.92^{\mathrm{c}}$ & $>1000$ & $3.82 \pm 0.42$ & $>100$ \\
\hline
\end{tabular}

* IC 50 values were determined by nonlinear regression analysis. Results are mean values \pm SD from three independent experiments; - , not tested; AA - ascorbic

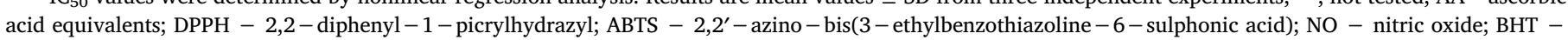
butylated hydroxytoluene. Means in the same column with different letters as superscripts are significantly different at $p<0.05$. 
<smiles>O=C(O)/C=C/c1ccc(O)c(O)c1</smiles>

Caffeic acid

$\left(\mathrm{C}_{9} \mathrm{H}_{8} \mathrm{O}_{4}\right)$<smiles>O=C(O)C(O)Cc1ccc(O)c(O)c1</smiles>

$\left(\mathrm{C}_{9} \mathrm{H}_{10} \mathrm{O}_{5}\right)$<smiles>O=C(/C=C/c1ccc(O)c(O)c1)OC(Cc1ccc(O)c(O)c1)C(=O)O</smiles>

Rosmarinic acid $\left(\mathrm{C}_{18} \mathrm{H}_{16} \mathrm{O}_{8}\right)$<smiles>O=C(/C=C/c1ccc(O)c2c1C(C(=O)O[C@H](Cc1ccc(O)c(O)c1)C(=O)O)[C@H](c1ccc(O)c(O)c1)O2)O[C@@H](Cc1ccc(O)c(O)c1)C(=O)O</smiles>

Salvianolic acid $B$ $\left(\mathrm{C}_{36} \mathrm{H}_{30} \mathrm{O}_{16}\right)$<smiles>CCCCCCCOC(=O)OC(Cc1ccc(O)c(O)c1)C(=O)OC(Cc1ccc(O)c(O)c1)C(=O)OC(Cc1ccc(O)c(O)c1)C(=O)O</smiles>

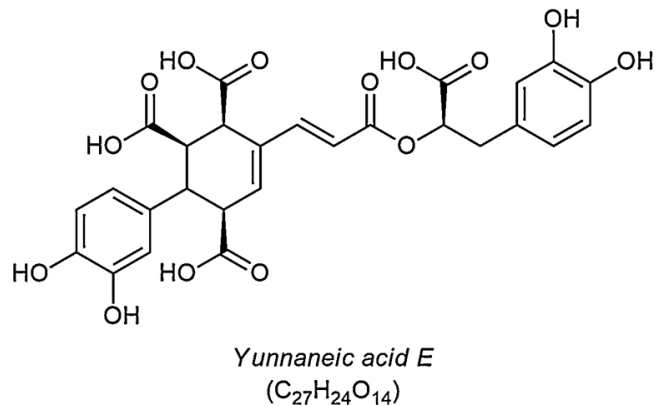

Fig. 3. Chemical structures of caffeic acid and its derivatives (mono-, di-, tri-, and tetramers) identified in the S. verticillata aerial part extract (SV).

that the amount of rosmarinic acid in SV $(67 \mathrm{mg} / \mathrm{g})$ is higher than the usual amounts found in other Salvia species. However, in this study, the concentration of rosmarinic acid in SV was much higher (ca. $235 \mathrm{mg} / \mathrm{g}$ ), consistently with the results of Tepe et al. (2007) who quantified similar levels of rosmarinic acid in methanol extracts of both subspecies of $S$. verticillata (subsp. verticillata and subsp. amasiaca). Besides polyphenolic compounds, characteristic Salvia diterpenes, including carnosic acid and carnosol (phenolic diterpene), were detected and quantified in this study. Carnosic acid was also detected in this plant by Šulniūté et al. (2017), but with no traces of carnosol. Generally, the aerial parts of Salvia spp. contain flavonoids, triterpenoids, and monoterpenes, mainly in the leaves and flowers, while the roots are rich in diterpenoids (Topçu, 2006). Moreover, Matkowski et al. (2008) reported that the levels of total phenolic content (TPC) in S. verticillata leaf and root extracts are quite similar, while Šulniūtè et al. (2016) showed that ethanolic extract of $S$. verticillata aerial parts was considerably richer in total phenolics than water extract. Our results also confirmed high TPC in SV extract, where flavonoids and phenolic acids were mostly present.

Salvia species are well-known for their broad spectrum of biological activities. One of the most prominent properties of the Lamiaceae family and, in particular, Salvia plants, is the antimicrobial activity. Besides S. officinalis (Gericke et al., 2018; Ghorbani and Esmaeilizadeh, 2017), many other members of this genus showed remarkable antimicrobial potential, for instance $S$. potentillifolia, $S$. verbenaca, $S$. chorassanica, $S$. veneris, etc., as it was recently very well summarized by Sharifi-Rad et al. (2018). The same authors reported that Salvia spp. showed significant bactericidal and bacteriostatic activities against both Gram-positive and Gram-negative bacteria, mostly Bacillus, Klebsiella, Pseudomonas, and Salmonella species, as well as microorganisms from Candida and Aspergillus spp. Therefore, Salvia antimicrobial properties are directed, to the highest point, against food spoilage and foodborne pathogens, in order to be used as a natural preservative in food applications (Sharifi-Rad et al., 2018; Tajkarimi et al., 2010). The antimicrobial potential of $S$. verticillata was not tested previously, so the results of this study showed, for the first time, the antimicrobial properties of $S$. verticillata extract, which were consistent with previously published data on Salvias' effects. SV showed antibacterial activity towards all tested bacterial strains, whereby the effects on Gram-positive strain B. cereus was particularly noteworthy, followed by B. mycoides, $M$. lysodeikticus, and Gram-negative A. chroococcum. The antifungal activity of SV was less notable, except for $P$. canescens and $C$. albicans. This potential is ascribed to the chemical composition of the extracts, mainly to the phenolic compounds presented in Salvia species. First and foremost compound, presented in high content in SV, is certainly rosmarinic acid, endowed with high antimicrobial potential towards a wide range of microbes, with minimal inhibitory concentration values (MIC) starting from $0.01 \mathrm{mg} / \mathrm{mL}$ (Abedini et al., 2013; Amoah et al., 2016). Also, many other phenolics detected in SV, e.g. phenolic acids, apigenin, luteolin, and quercetin derivatives (Cushnie and Lamb, 2005), 
and diterpenoids like carnosol and carnosic acid (Ghorbani and Esmaeilizadeh, 2017), exert antibacterial and antifungal potential due to the high presence of $-\mathrm{OH}$ groups which play an important role in the antimicrobial activity (trough the interaction with the cell membrane, delocalization of electrons, binding the active site of enzymes, and leading to the microorganisms growth restriction) (Gyawali and Ibrahim, 2014). Although the extracts of Salvia species generally have good antimicrobial properties, Salvia essential oils are mostly used due to the high content of volatile antimicrobial compounds like $\alpha$-thujene, $\alpha$ - and $\beta$-pinene, myrcene, limonene, etc., which were also identified in S. verticillata essential oil (Giuliani et al., 2018; Pitarokili et al., 2006; Rzepa et al., 2009). As SV extract had moderate antimicrobial activity, perhaps the more justified use of SV in this sense would be in the form of essential oil.

Besides antimicrobial activity, phenolic compounds are recognized for their prominent antioxidant effects. Their hydrogen atom donating potential render them exceptionally efficacious antioxidants, with different mechanisms of action counteracting oxidative stress in materials and organisms (Brewer, 2011). They can interfere with the process of free radical generation in phases of initiation or propagation, and sometimes even as metal chelators, they have the ability to activate antioxidant enzymes and modification of prooxidant properties of low molecular antioxidants (Procházková et al., 2011; Shahidi and Ambigaipalan, 2015). Many of them are in use in the food industry as food additives for preventing lipid oxidation and therefore extending the shelf-life of food products without any influence on the food nutritional quality and sensory properties (Shahidi and Ambigaipalan, 2015). Regarding Lamiaceae plants, numerous members of this family and one of their main phenolic compounds, rosmarinic acid, are used in industrial applications for cosmetic and food products, because of significant antioxidant activity (Trivellini et al., 2016). Since the tested $S$. verticillata aerial part extract contains a high content of phenolic compounds, known to act as antioxidants, it is not surprising that SV extract exerts good total antioxidant capacity and scavenging potential towards different free radicals. Šulniūtè et al. (2016) reported good ABTS ${ }^{+}$ scavenging activity and high ORAC values of different $S$. verticillata aerial part extracts, while Matkowski et al. (2008) showed that the root extract had better ABTS $^{+}$scavenging activity than its leaves, but lower reducing power and DPPH antioxidant potential. Moreover, in a study from Tepe et al. (2007), it was shown that both $S$. verticillata subspecies (subsp. verticillata and amasiaca) exerted similar free radical-scavenging capacities and the inhibition ratio of linoleic acid oxidation, comparable to the effects of rosmarinic acid. Several other studies described the antioxidant activity of $S$. verticillata subsp. amasiaca against free radicals, as well as chelating and reducing potential (Orhan et al., 2007, 2013; Zengin et al., 2018). Thus, the traditional use of $S$. verticillata in preparing cheese and meat products is supported by these results, since its antioxidant capacity helps to prevent food quality deterioration. Like many other members of the Lamiaceae family (rosemary, sage, basil, oregano, marjoram, savory, and thyme), rich in rosmarinic acid and other proven antioxidant compounds (Brewer, 2011), S. verticillata extract may also be included in the food industry for different purposes. In that sense, the biocompatibility of the extract is very important for its implementation in the human diet and incorporation in human-used products.

Taking into account the content of diverse phenolic compounds with proven bioactivity, it is surprising that there is no literature data related to the influence of $S$. verticillata extract on eukaryotic cell lines. Our results showed, for the first time, that SV was not toxic towards murine immortalized fibroblasts (BalbC-3T3) and human immortalized epidermal keratinocytes (HaCaT) in all tested concentrations. Moreover, there were no significant cytotoxic effects on three cancer cell lines (A431, HepG2, and LoVo), except at the highest concentration of SV. Zengin et al. (2018) confirmed the absence of antiproliferative activity of $S$. verticillata subsp. amasiaca on human alveolar lung epithelial carcinoma (A549) and human breast adenocarcinoma (MCF-7), as well as its influence on inhibition of some key enzymes (cholinesterases, tyrosinase, glucosidase, amylase, lipase, and elastase) in different illnesses of modern age, such as Alzheimer's disease, diabetes mellitus, and obesity.

\section{Conclusion}

The results showed that a methanol extract from $S$. verticillata aerial parts is quite rich in phenolic compounds, particularly rosmarinic acid and its derivatives. The extract exerted good antimicrobial activity against some of the selected bacteria and fungi species. Also, SV extract exhibited prominent antioxidant properties and antiradical potential, comparable to referent antioxidants. Its action on normal and cancer cell lines indicates high biocompatibility and absence of cytotoxicity. The observed results suggested that $S$. verticillata should not be considered just like a weed plant, but rather as a rich source of compounds with prominent bioactive properties and as a potential additive in food or cosmetic industries, with further exploration of concrete possibilities of use and extract standardization.

\section{Declaration of Competing Interest}

The authors declare no conflict of interest.

\section{Acknowledgment}

This research was supported by the Ministry of Education, Science and Technological Development of the Republic of Serbia (project Nos. III 43004, OI172017, and OI173024).

\section{Appendix A. Supplementary data}

Supplementary material related to this article can be found, in the online version, at doi:https://doi.org/10.1016/j.indcrop.2019.111932.

\section{References}

Abedini, A., Roumy, V., Mahieux, S., Biabiany, M., Standaert-Vitse, A., Rivière, C., Sahpaz, S., Bailleul, F., Neut, C., Hennebelle, T., 2013. Rosmarinic acid and its methyl ester as antimicrobial components of the hydromethanolic extract of Hyptis atrorubens Poit. (Lamiaceae). Evid. Complement. Alternat. Med. 2013, 604536. https://doi.org/ $10.1155 / 2013 / 604536$

Amoah, S.K.S., Sandjo, L.P., Kratz, J.M., Biavatti, M.W., 2016. Rosmarinic acid - pharmaceutical and clinical aspects. Planta Med. 82, 388-406. https://doi.org/10.1055/ s-0035-1568274.

Boroja, T., Katanić, J., Rosić, G., Selaković, D., Joksimović, J., Mišić, D., Stanković, V., Jovičić, N., Mihailović, V., 2018. Summer savory (Satureja hortensis L.) extract: phytochemical profile and modulation of cisplatin-induced liver, renal and testicular toxicity. Food Chem. Toxicol. 118, 252-263. https://doi.org/10.1016/j.fct.2018.05. 001.

Božunović, J., Živković, S., Gašić, U., Glamočlija, J., Ćirić, A., Matekalo, D., Šiler, B., Soković, M., Tešić, Ž., Mišić, D., 2018. In vitro and in vivo transformations of Centaurium erythraea secoiridoid glucosides alternate their antioxidant and antimicrobial capacity. Ind. Crops Prod. 111, 705-721. https://doi.org/10.1016/J. INDCROP. 2017.11.040.

Brewer, M.S., 2011. Natural antioxidants: sources, compounds, mechanisms of action, and potential applications. Compr. Rev. Food Sci. Food Saf. 10, 221-247. https://doi. org/10.1111/j.1541-4337.2011.00156.x.

Brighente, I.M.C., Dias, M., Verdi, L.G., Pizzolatti, M.G., 2007. Antioxidant activity and total phenolic content of some brazilian species. Pharm. Biol. 45, 156-161. https:// doi.org/10.1080/13880200601113131.

Chen, W., Chen, G., 2018. Danshen (Salvia miltiorrhiza Bunge): a prospective healing sage for cardiovascular diseases. Curr. Pharm. Des. 23. https://doi.org/10.2174/ 1381612823666170822101112.

CLSI, 2012. Methods for Dilution Antimicrobial Susceptibility Tests for Bacteria That Grow Aerobically; Approved Standard - Ninth Edition, vol. 32 Clinical and Laboratory Standards Institute (CLSI), Wayne, PA, USA.

Cushnie, T.P.T., Lamb, A.J., 2005. Antimicrobial activity of flavonoids. Int. J. Antimicrob. Agents 26, 343-356. https://doi.org/10.1016/j.ijantimicag.2005.09.002.

European Medicines Agency, 2016. European Union Herbal Monograph on Salvia officinalis L., folium. Accessed: 06.05.2019.

Forouzin, F., Jamei, R., Heidari, R., 2015. Compositional analysis and antioxidant activity of volatile components of two Salvia spp. Trop. J. Pharm. Res. 14, 2009-2013. https://doi.org/10.4314/tjpr.v14i11.9. 
Gericke, S., Lübken, T., Wolf, D., Kaiser, M., Hannig, C., Speer, K., 2018. Identification of new compounds from sage flowers (Salvia officinalis L.) as markers for quality control and the influence of the manufacturing technology on the chemical composition and antibacterial activity of sage flower extracts. J. Agric. Food Chem. 66, 1843-1853. https://doi.org/10.1021/acs.jafc.8b00581.

Ghorbani, A., Esmaeilizadeh, M., 2017. Pharmacological properties of Salvia officinalis and its components. J. Tradit. Complement. Med. 7, 433-440. https://doi.org/10. 1016/J.JTCME.2016.12.014.

Giuliani, C., Ascrizzi, R., Lupi, D., Tassera, G., Santagostini, L., Giovanetti, M., Flamini, G., Fico, G., 2018. Salvia verticillata: linking glandular trichomes, volatiles and pollinators. Phytochemistry 155, 53-60. https://doi.org/10.1016/j.phytochem.2018.07. 016.

Green, L.C., Wagner, D.A., Glogowski, J., Skipper, P.L., Wishnok, J.S., Tannenbaum, S.R., 1982. Analysis of nitrate, nitrite, and [15N]nitrate in biological fluids. Anal. Biochem. 126, 131-138. https://doi.org/10.1016/0003-2697(82)90118-X.

Gyawali, R., Ibrahim, S.A., 2014. Natural products as antimicrobial agents. Food Control 46, 412-429. https://doi.org/10.1016/j.foodcont.2014.05.047.

Hsu, C.-K., Chiang, B.-H., Chen, Y.-S., Yang, J.-H., Liu, C.-L., 2008. Improving the antioxidant activity of buckwheat (Fagopyrum tataricm Gaertn) sprout with trace element water. Food Chem. 108, 633-641. https://doi.org/10.1016/j.foodchem.2007.11.028.

Jarić, S., Mačukanović-Jocić, M., Djurdjević, L., Mitrović, M., Kostić, O., Karadžić, B., Pavlović, P., 2015. An ethnobotanical survey of traditionally used plants on Suva planina mountain (south-eastern Serbia). J. Ethnopharmacol. 175, 93-108. https:// doi.org/10.1016/j.jep.2015.09.002.

Jassbi, A.R., Zare, S., Firuzi, O., Xiao, J., 2016. Bioactive phytochemicals from shoots and roots of Salvia species. Phytochem. Rev. 15, 829-867. https://doi.org/10.1007/ s11101-015-9427-z.

Kumarasamy, Y., Byres, M., Cox, P.J., Jaspars, M., Nahar, L., Sarker, S.D., 2007. Screening seeds of some Scottish plants for free radical scavenging activity. Phyther. Res. 21, 615-621. https://doi.org/10.1002/ptr.2129.

Li, M., Wang, F., Huang, Y., Du, F., Zhong, C., Olaleye, O.E., Jia, W., Li, Y., Xu, F., Dong, J., Li, J., Lim, J.B.R., Zhao, B., Jia, L., Li, L., Li, C., 2015. Systemic exposure to and disposition of catechols derived from Salvia miltiorrhiza roots (Danshen) after intravenous dosing danhong injection in human subjects, rats, and dogs. Drug Metab. Dispos. 43, 679-690. https://doi.org/10.1124/dmd.114.061473.

Lu, Y., Yeap Foo, L., 2002. Polyphenolics of Salvia - a review. Phytochemistry 59, 117-140. https://doi.org/10.1016/S0031-9422(01)00415-0.

Matkowski, A., Zielińska, S., Oszmiański, J., Lamer-Zarawska, E., 2008. Antioxidant activity of extracts from leaves and roots of Salvia miltiorrhiza Bunge, S. przewalskii Maxim., and S. verticillata L. Bioresour. Technol. 99, 7892-7896. https://doi.org/10. 1016/j.biortech.2008.02.013.

Mišić, D., Šiler, B., Gašić, U., Avramov, S., Živković, S., Nestorović Živković, J., Milutinović, M., Tešić, Ž., 2015. Simultaneous UHPLC/DAD/(+/-)HESI-MS/MS analysis of phenolic acids and nepetalactones in methanol extracts of Nepetaspecies: A possible application in chemotaxonomic studies. Phytochem. Anal. 26, 72-85. https://doi.org/10.1002/pca.2538.

NCCLS, 2002a. Reference Method for Broth Dilution Antifungal Susceptibility Testing of Filamentous Fungi; Approved Standard. NCCLS Document M38-A. [ISBN 1-56238470-8]. NCCLS, 940 West Valley Road, Suite 1400,Wayne, Pennsylvania 19087-1898 USA.

NCCLS, 2002b. Reference Method for Broth Dilution Antifungal Susceptibility Testing of Yeasts; Approved Standard - Second Edition. NCCLS Document M27-A2. [ISBN 156238-469-4]. NCCLS, 940 West Valley Road, Suite 1400, Wayne, Pennsylvania 19087-1898 USA.

Orhan, I., Kartal, M., Naz, Q., Ejaz, A., Yilmaz, G., Kan, Y., Konuklugil, B., Sener, B., Iqbal Choudhary, M., 2007. Antioxidant and anticholinesterase evaluation of selected Turkish Salvia species. Food Chem. 103, 1247-1254. https://doi.org/10.1016/j. foodchem.2006.10.030.

Orhan, I.E., Senol, F.S., Ercetin, T., Kahraman, A., Celep, F., Akaydin, G., Sener, B., Dogan, M., 2013. Assessment of anticholinesterase and antioxidant properties of selected sage (Salvia) species with their total phenol and flavonoid contents. Ind. Crops Prod. 41, 21-30. https://doi.org/10.1016/j.indcrop.2012.04.002.

Öztürk, N., Tunçel, M., Uysal, U.D., Oncu-Kaya, E.M., Koyuncu, O., 2011. Determination of rosmarinic acid by high-performance liquid chromatography and its application to certain Salvia species and rosemary. Food Anal. Methods 4, 300-306. https://doi.org/ 10.1007/s12161-010-9164-2.

Parker, J., Schellenberger, A.N., Roe, A.L., Oketch-Rabah, H., Calderón, A.I., 2018. Therapeutic perspectives on chia seed and its oil: a review. Planta Med. 84, 606-612. https://doi.org/10.1055/a-0586-4711.

Petruk, G., Raiola, A., Del Giudice, R., Barone, A., Frusciante, L., Rigano, M.M., Monti, D.M., 2016. An ascorbic acid-enriched tomato genotype to fight UVA-induced oxidative stress in normal human keratinocytes. J. Photochem. Photobiol. B, Biol. 163, 284-289. https://doi.org/10.1016/J.JPHOTOBIOL.2016.08.047.

Pitarokili, D., Tzakou, O., Loukis, A., 2006. Essential oil composition of Salvia verticillata, $S$. verbenaca, S. glutinosa and S. candidissima growing wild in Greece. Flavour Fragr. J. 21, 670-673. https://doi.org/10.1002/ffj.1647.

Prieto, P., Pineda, M., Aguilar, M., 1999. Spectrophotometric quantitation of antioxidant capacity through the formation of a phosphomolybdenum complex: specific application to the determination of vitamin E. Anal. Biochem. 269, 337-341. https:// doi.org/10.1006/abio.1999.4019.

Procházková, D., Boušová, I., Wilhelmová, N., 2011. Antioxidant and prooxidant properties of flavonoids. Fitoterapia 82, 513-523. https://doi.org/10.1016/j.fitote.2011. 01.018.

Re, R., Pellegrini, N., Proteggente, A., Pannala, A., Yang, M., Rice-Evans, C., 1999. Antioxidant activity applying an improved ABTS radical cation decolorization assay. Free Radic. Biol. Med. 26, 1231-1237. https://doi.org/10.1016/S0891-5849(98) 00315-3.

Rzepa, J., Wojtal, Ł., Staszek, D., Grygierczyk, G., Labe, K., Hajnos, M., Kowalska, T., Waksmundzka-Hajnos, M., 2009. Fingerprint of selected Salvia species by HS-GC-MS analysis of their volatile fraction. J. Chromatogr. Sci. 47, 575-580. https://doi.org/ 10.1093/chromsci/47.7.575.

Sarker, S.D., Nahar, L., Kumarasamy, Y., 2007. Microtitre plate-based antibacterial assay incorporating resazurin as an indicator of cell growth, and its application in the in vitro antibacterial screening of phytochemicals. Methods 42, 321-324. https://doi. org/10.1016/j.ymeth.2007.01.006.

Shahidi, F., Ambigaipalan, P., 2015. Phenolics and polyphenolics in foods, beverages and spices: antioxidant activity and health effects - a review. J. Funct. Foods 18 , 820-897. https://doi.org/10.1016/j.jff.2015.06.018.

Sharifi-Rad, M., Ozcelik, B., Altın, G., Daşkaya-Dikmen, C., Martorell, M., RamírezAlarcón, K., Alarcón-Zapata, P., Morais-Braga, M.F.B., Carneiro, J.N.P., Borges, Alves, Leal, A.L., Coutinho, H.D.M., Gyawali, R., Tahergorabi, R., Ibrahim, S.A., Sahrifi-Rad, R., Sharopov, F., Salehi, B., del Mar Contreras, M., Segura-Carretero, A., Sen, S. Acharya, K., Sharifi-Rad, J., 2018. Salvia spp. Plants-from farm to food applications and phytopharmacotherapy. Trends Food Sci. Technol. https://doi.org/10.1016/j. tifs.2018.08.008.

Singleton, V.L., Orthofer, R., Lamuela-Raventós, R.M., 1999. Analysis of total phenols and other oxidation substrates and antioxidants by means of Folin-Ciocalteu reagent. Methods Enzymol. 299, 152-178. https://doi.org/10.1016/S0076-6879(99)99017-1.

Šulniūtè, V., Pukalskas, A., Venskutonis, P.R., 2017. Phytochemical composition of fractions isolated from ten Salvia species by supercritical carbon dioxide and pressurized liquid extraction methods. Food Chem. 224, 37-47. https://doi.org/10.1016/ j.foodchem.2016.12.047.

Šulniūtè, V., Ragažinskienè, O., Venskutonis, P.R., 2016. Comprehensive evaluation of antioxidant potential of 10 Salvia species using high pressure methods for the isolation of lipophilic and hydrophilic plant fractions. Plant Foods Hum. Nutr. 71, 64-71. https://doi.org/10.1007/s11130-015-0526-1.

Tajkarimi, M.M., Ibrahim, S.A., Cliver, D.O., 2010. Antimicrobial herb and spice compounds in food. Food Control 21, 1199-1218. https://doi.org/10.1016/j.foodcont. 2010.02.003.

Tepe, B., Eminagaoglu, O., Akpulat, H.A., Aydin, E., 2007. Antioxidant potentials and rosmarinic acid levels of the methanolic extracts ofSalvia verticillata (L.) subsp. verticillata and S. verticillata (L.) subsp. amasiaca (Freyn \& Bornm.) Bornm. Food Chem. 100, 985-989. https://doi.org/10.1016/j.foodchem.2005.10.062.

Topçu, G., 2006. Bioactive triterpenoids from Salvia species. J. Nat. Prod. 69, 482-487. https://doi.org/10.1021/np0600402.

Trivellini, A., Lucchesini, M., Maggini, R., Mosadegh, H., Villamarin, T.S.S., Vernieri, P., Mensuali-Sodi, A., Pardossi, A., 2016. Lamiaceae phenols as multifaceted compounds: bioactivity, industrial prospects and role of "positive-stress.". Ind. Crops Prod. https://doi.org/10.1016/j.indcrop.2015.12.039.

Ulubelen, A., Topcu, G., 1984. Flavonoids and terpenoids from Salvia verticillata and Salvia pinnata. J. Nat. Prod. 47, 1068.

Walker, J.B., Sytsma, K.J., Treutlein, J., Wink, M., 2004. Salvia (Lamiaceae) is not monophyletic: implications for the systematics, radiation, and ecological specializations of Salvia and tribe Mentheae. Am. J. Bot. 91, 1115-1125. https://doi.org/10. 3732/ajb.91.7.1115.

Wu, Y., Ni, Z., Shi, Q., Dong, M., Kiyota, H., Gu, Y., Cong, B., 2012. Constituents from Salvia species and their biological activities. Chem. Rev. 112, 5967-6026. https:// doi.org/10.1021/cr200058f.

Xu, J., Wei, K., Zhang, G., Lei, L., Yang, D., Wang, W., Han, Q., Xia, Y., Bi, Y., Yang, M., Li, M., 2018. Ethnopharmacology, phytochemistry, and pharmacology of Chinese Salvia species: a review. J. Ethnopharmacol. 225, 18-30. https://doi.org/10.1016/J.JEP. 2018.06.029.

Yan, L., Teng, L., Jhi, T., 2006. Antioxidant properties of guava fruits: comparison with some local fruits. Sunw. Acad. J. 3, 9-20.

Yermakov, A.I., Arasimov, V.V., Yarosh, N.P., 1987. Methods of Biochemical Analysis of Plants. Agropromizdat, Leningrad.

Zengin, G., Llorent-Martínez, E.J., Córdova, M.L.Fde, Bahadori, M.B., Mocan, A Locatelli, M., Aktumsek, A., 2018. Chemical composition and biological activities of extracts from three Salvia species: S. blepharochlaena, S. euphratica var. leiocalycina, and $S$. verticillata subsp. amasiaca. Ind. Crops Prod. 111, 11-21. https://doi.org/10. 1016/j.indcrop.2017.09.065.

Zhang, Q., Yang, H., An, J., Zhang, R., Chen, B., Hao, D.-J., 2016. Therapeutic effects of Traditional Chinese medicine on spinal cord injury: a promising supplementary treatment in future. Evid. Complement. Alternat. Med. 2016, 1-18. https://doi.org/ $10.1155 / 2016 / 8958721$. 